Fetal Diagnosis and Therapy
Fetal Diagn Ther

DOI: $10.1159 / 000381802$
Received: September 15, 2014

Accept after revision: March 12, 2015

Published online: June 17, 2015

\title{
Development of Late-Onset Preeclampsia in Association with Road Densities as a Proxy for Traffic-Related Air Pollution
}

\author{
Meng $\mathrm{Wu}^{\mathrm{a}} \quad$ Jean-Jacques Ries ${ }^{\mathrm{a}}$ Elena Proietti ${ }^{\mathrm{d}}$ Deborah Vogt ${ }^{\mathrm{b}}$ Sinuhe Hahn ${ }^{\mathrm{c}}$ \\ Irene Hoeslia \\ ${ }^{a}$ Department of Obstetrics and Fetomaternal Medicine, ${ }^{b} \mathrm{Clinical}$ Trial Unit, and ${ }^{\mathrm{c} D e p a r t m e n t}$ of Biomedicine, \\ University Hospital of Basel, and ${ }^{\mathrm{d}}$ Department of Pediatrics, University Children's Hospital Basel, Basel, Switzerland
}

\author{
Key Words \\ Preeclampsia · Perinatal outcome · Placenta - Pregnancy \\ complications - Air pollution - Traffic · Road density . \\ Late-onset preeclampsia
}

\begin{abstract}
Introduction: Previous epidemiological studies indicate an association between maternal exposure to air pollution and an increased risk of hypertensive disorders in pregnancy. We analyzed the association between the occurrence of mild/ severe and early-/late-onset preeclampsia (PE) and trafficrelated air pollution (TRAP). Materials and Methods: Based on retrospective data, 50 pregnant women with PE were selected and matched with a control group of healthy pregnant women according to their age, parity, and number of fetuses. The total length of major roads around the women's home within a radius of $100,200,300$, and $500 \mathrm{~m}$ and the distances from the domicile to the nearest 'first class' main road and freeway were used as a proxy indicator of TRAP. We compared a PE subgroup and control group in terms of their exposure to TRAP. Results: Late-onset PE cases showed a significantly higher occurrence with density of major roads within a radius of 100-300 m compared to early onset cases $(p=0.006 ; 0.02 ; 0.04)$. In addition, a significantly shorter distance to the nearest 'first class' main road was observed in
\end{abstract}

\section{KARGER 125}

(c) 2015 S. Karger AG, Base

$1015-3837 / 15 / 0000-0000 \$ 39.50 / 0$

E-Mail karger@karger.com

www.karger.com/fdt late-onset PE cases $(p=0.0078)$. Conclusions: Exposure to TRAP during pregnancy was associated with an increased risk for the development of late-onset PE.

(c) 2015 S. Karger AG, Basel

\section{Introduction}

Preeclampsia (PE) is a serious complication of the second half of pregnancy in up to $8 \%$ of all pregnancies. It is one of the 3 leading causes of maternal morbidity and mortality worldwide [1]. PE is clinically defined as the new onset of hypertension (blood pressure $\geq 140 / 90 \mathrm{~mm} \mathrm{Hg}$ at least on 2 measurements $6 \mathrm{~h}$ apart from each other) and significant proteinuria $(>0.3 \mathrm{~g} / 24 \mathrm{~h}$ ) after 20 weeks of gestation. The severe type of PE is specified as hypertension

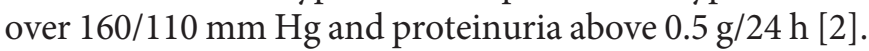
Furthermore, signs of a significant organ involvement like neurological symptoms, renal failure or HELLP syndrome (hemolysis, elevated liver enzymes, and low platelet) belong to the category of severe PE [3]. Depending on the time of appearance of the first clinical symptoms, PE can also be classified into 2 distinct subtypes. Early onset is defined as less than 34 weeks of gestation, while late-onset is

M. W. and J.-J. R. contributed equally to this work. 
defined as after $34+0$ weeks of gestation [1, 4-7]. Earlyonset $\mathrm{PE}$ is a rare disease with a high maternal and neonatal morbidity and mortality [5]. Late-onset PE, however, has a lower maternal and fetal morbidity and occurs more frequently. Besides the different clinical aspects and maternal and fetal outcomes, there is a discussion about different etiologies of these 2 subtypes. Several studies propose that generalized endothelial dysfunctions in the placenta and the impaired trophoblastic invasion of the maternal placental bed in early pregnancy might be the origins of the early-onset disease [3]. These 2 factors may lead to systemic endothelial cell dysfunction and systemic inflammation with neutrophil activation in the maternal body $[8,9]$. PE presenting at term is associated with a lower frequency and severity of fetal growth restriction compared to early-onset PE. Late-onset PE could be hypothesized to present a process leading to maternal endothelial damage, which is unrelated to impaired early trophoblast invasion [10]. Predisposing cardiovascular factors or metabolic risks for endothelial dysfunction as part of an exaggerated systemic inflammatory response might dominate the origin of lateonset PE [11-13]. Currently, the only causal treatment for $\mathrm{PE}$ is delivery and the removal of the placenta. The prediction of $\mathrm{PE}$ is a major challenge in contemporary obstetrics, and some authors could recently show added value of angiogenic factors for the prediction of early- and late-onset $\mathrm{PE}$ in the first trimester of pregnancy [14].

Major risk factors for the development of $\mathrm{PE}[12,15]$ are previous chronic hypertension, kidney disease, diabetes mellitus, nulliparity, obesity, multiple pregnancies, maternal age $>40$ years, African-American race [16], and family history of PE. It is known that local air pollution exposure, especially pollution due to motor vehicle traffic [17], is associated with adverse cardiovascular and respiratory effects like systemic inflammation, elevated blood pressure and asthma $[18,19]$. Previous studies also indicate a potential harmful effect of local air pollution on pregnancy outcome, including an increased risk of preterm delivery and PE [20-22]. Recently, a meta-analysis including 17 studies evaluated the exposure to ambient air pollution and pregnancy-induced hypertensive disorders. Most studies measured air pollutant levels like nitrogen oxides $\left(\mathrm{NO}_{2}, \mathrm{NO}_{\mathrm{x}}\right)$, particulate matter $\left(\mathrm{PM}_{10}, \mathrm{PM}_{2.5}\right)$, carbon monoxide $(\mathrm{CO})$, ozone $\left(\mathrm{O}_{3}\right)$, but few took traffic density and the proximity to major roads into account, which can be used as estimates of air pollution. The meta-analysis showed an increased risk of hypertensive disorders in pregnancy including all pollutants as well as the proximity to major roads and traffic density [23]. In this context, several studies have reported that traffic-related air pollution (TRAP) is associated with endothelial dysfunction, a potential predictor of $\mathrm{PE}$ $[24,25]$. Air pollutants may also contribute to an anti-angiogenic state which can also lead to PE [26]. The aim of the present study was to analyze the association between the occurrence of PE and TRAP in the North Western area of Switzerland in a case-control study. The PE cases were stratified into mild/severe and early-/late-onset subgroups according to the common definitions [6] and analyzed for their association with air pollution.

\section{Materials and Methods}

\section{Study Design and Study Population}

This case-control study was performed at the University Hospital of Basel, Switzerland. The catchment area of the study was the Canton of Basel-City and its surroundings (Canton of BaselCountry). A few study participants were enrolled from the Cantons of Aargau, Solothurn, Zurich and Berne. Based on retrospective data from the electronic medical records of the Department of Obstetrics and Fetomaternal Medicine and the home addresses, indicated at booking, 50 pregnant women were selected for the study group. These women were treated for PE and sent to our institution between January 1, 2011, and December 31, 2011. The criteria included were all singleton or multiple pregnancies after $20+0$ weeks of gestation. The excluded criteria were pregnancies before the $20+0$ weeks of gestation, the women's domicile outside of Switzerland, women with an abortion due to PE or eclampsia before the 24th week of gestation as well as fetuses with severe malformation. The study group was matched with a healthy control group of 50 pregnant women with uncomplicated pregnancies. Age at delivery ( \pm 1year, if necessary), parity and number of fetuses (singleton or twin pregnancy) were used as matching criteria. According to our statistics, there were 79 women in total treated for PE at the University Hospital of Basel in 2011. Overall, 2,286 births' were registered at our institution. This study was approved by the Ethics Committee of Basel (Ethikkommission beider Basel).

\section{TRAP Exposure}

In the present study, the exposure to TRAP, especially nitrogen dioxide $\left(\mathrm{NO}_{2}\right)$, particulate matter $\left(\mathrm{PM}_{2.5}, \mathrm{PM}_{10}\right)$, sulfur dioxide $\left(\mathrm{SO}_{2}\right)$ and carbon monoxide ( $\left.\mathrm{CO}\right)$ [27], was estimated by a surrogate measure of road density in the surroundings, in particular the densities of major roads, which is defined as a combination of all freeways and 'first class' main roads (at least 6 m wide) $[28,29]$. The geographic information system (GIS) data with the road network of Switzerland was provided by the Swiss Federal Office of Topography (swisstopo) [30]. Two parameters for estimating the road density were defined; first, the total length of all major roads within a radius of $100,200,300$, and $500 \mathrm{~m}$ around the geocoded location of each woman's home during their pregnancy, and second, the distance in meters from each woman's domicile to the nearest 'first class' main road and freeway.

\section{Statistical Analysis}

The statistical data set included a total of 100 pregnant women, whereof 50 women developed PE during pregnancy (study group) and 50 women showed no health problems (control group). PE cas- 
es differed in severity, 'mild' or 'severe', and in time of onset, 'early' or 'late'. Mean, standard deviation, median, minimum and maximum for each road density parameter were calculated for each group. Both case and control groups as well as each PE subgroup (mild vs. severe; early vs. late onset) were compared by a MannWhitney test. Statistically significant results were defined as $\mathrm{p} \leq 0.05$.

Maternal and fetal characteristics were measured and differences between the case and control groups were tested using Fisher's exact test for continuous variables and the Kruskal-Wallis rank-sum test for categorical variables. $p$ values were not adjusted for multiple testing. We did not perform a power calculation. Our main objective was the comparison between the case and control group.

\section{Results}

\section{Subject Characteristics}

We included 100 pregnant women and 106 newborns in the study. Maternal and fetal characteristics are represented in tables 1 and 2 . The control group was matched for maternal age and parity, but, due to the retrospective design and logistical restrictions, not for other risk factors like hypertension, previous $\mathrm{PE}$ or twin pregnancy, which could increase the risk for PE. All relevant diseases were absent in the control group, with the exception of 1 case of asthma (table 1: 'other disease'). There were 2 women with gestational diabetes and 2 with preconceptional diabetes. Newborns from mothers suffering from PE had a preterm birth more often, were born by cesarean section and transferred to the neonatal intensive care unit.

\section{Cases versus Control}

Figures 1 and 2 show the descriptive analyses of road density parameters for the study versus the control group. The control group showed a significantly higher total length of major roads within a radius of $500 \mathrm{~m}$ compared to the study group (fig. 1). For all other road density parameters, no statistically significant difference between study and control group was found.

\section{Early-versus Late-Onset PE Cases}

Descriptive analyses of road density parameters for early- versus late-onset PE cases are shown in figures 3 and 4 .

Late-onset PE cases showed a significantly higher occurrence with a total length of major roads within a radius of 100, 200, and $300 \mathrm{~m}$ (fig. 3) and a significantly shorter distance to the nearest 'first class' main road compared to early-onset PE cases (fig. 4). In addition, in lateonset PE cases, both a higher total length of major roads within a radius of $500 \mathrm{~m}$ and a shorter distance to the
Table 1. Description of Maternal characteristics

\begin{tabular}{|c|c|c|c|}
\hline Maternal characteristics & Case & Control & $\mathrm{p}$ value \\
\hline Patient, $\mathrm{n}$ & 50 & 50 & 1.00 \\
\hline Age at delivery, years & $32.02 \pm 5.75$ & $32 \pm 5.61$ & 0.99 \\
\hline \multicolumn{3}{|l|}{ Insurance status } & \multirow[t]{3}{*}{0.80} \\
\hline Private & $9(18)$ & $11(22)$ & \\
\hline Nonprivate & $41(82)$ & $39(78)$ & \\
\hline \multicolumn{3}{|l|}{ Origin } & \multirow[t]{3}{*}{0.26} \\
\hline Europe & $40(80)$ & $45(90)$ & \\
\hline Others & $10(20)$ & $5(10)$ & \\
\hline \multicolumn{3}{|l|}{ Domicile in } & \multirow[t]{3}{*}{0.26} \\
\hline City & $40(80)$ & $45(90)$ & \\
\hline Countryside & $10(20)$ & $5(10)$ & \\
\hline BMI & $30.08 \pm 5.68$ & $26.76 \pm 3.93$ & 0.007 \\
\hline \multicolumn{3}{|l|}{ Parity } & \multirow[t]{4}{*}{1.00} \\
\hline 1 & $38(76)$ & $38(76)$ & \\
\hline 2 & $8(16)$ & $8(16)$ & \\
\hline$>2$ & $4(8)$ & $4(8)$ & \\
\hline \multicolumn{3}{|l|}{ Pregnancy modus } & \multirow[t]{3}{*}{0.06} \\
\hline Spontaneous & $43(86)$ & $49(98)$ & \\
\hline Infertility treatment & $7(14)$ & $1(2)$ & \\
\hline \multicolumn{4}{|l|}{ Number of fetuses } \\
\hline Singleton & $47(94)$ & $47(94)$ & \multirow[t]{2}{*}{1.00} \\
\hline Twins & $3(6)$ & $3(6)$ & \\
\hline \multicolumn{4}{|l|}{ Relevant diseases } \\
\hline Earlier PE & $5(10)$ & $0(0)$ & \\
\hline \multicolumn{4}{|l|}{ Diabetes mellitus and } \\
\hline Hypertension & $5(10)$ & $0(0)$ & \\
\hline Others ${ }^{1}$ & $7(14)$ & $1(2)$ & \\
\hline \multicolumn{4}{|l|}{ PE severity } \\
\hline Mild & $10(20)$ & & \\
\hline Severe & $40(80)$ & & \\
\hline HELLP & $12(24)$ & & \\
\hline \multicolumn{4}{|l|}{ PE onset } \\
\hline Early onset & $24(48)$ & & \\
\hline Late onset & $26(52)$ & & \\
\hline
\end{tabular}

Values represent mean $\pm \mathrm{SD}$ or $\mathrm{n}(\%)$.

1 Chronic kidney disease, asthma bronchiale or cigarette consumption.

nearest freeway were found, although these differences were not statistically significant.

\section{Mild versus Severe PE Cases}

No significant difference was found in any road density parameter between severe and mild PE cases. However, some tendency in the results could be observed: severe $\mathrm{PE}$ cases showed a higher total length of major roads within all radiuses (fig. 5) and a shorter distance to the nearest freeway and to the nearest 'first class' main road compared to mild PE cases (fig. 6). 


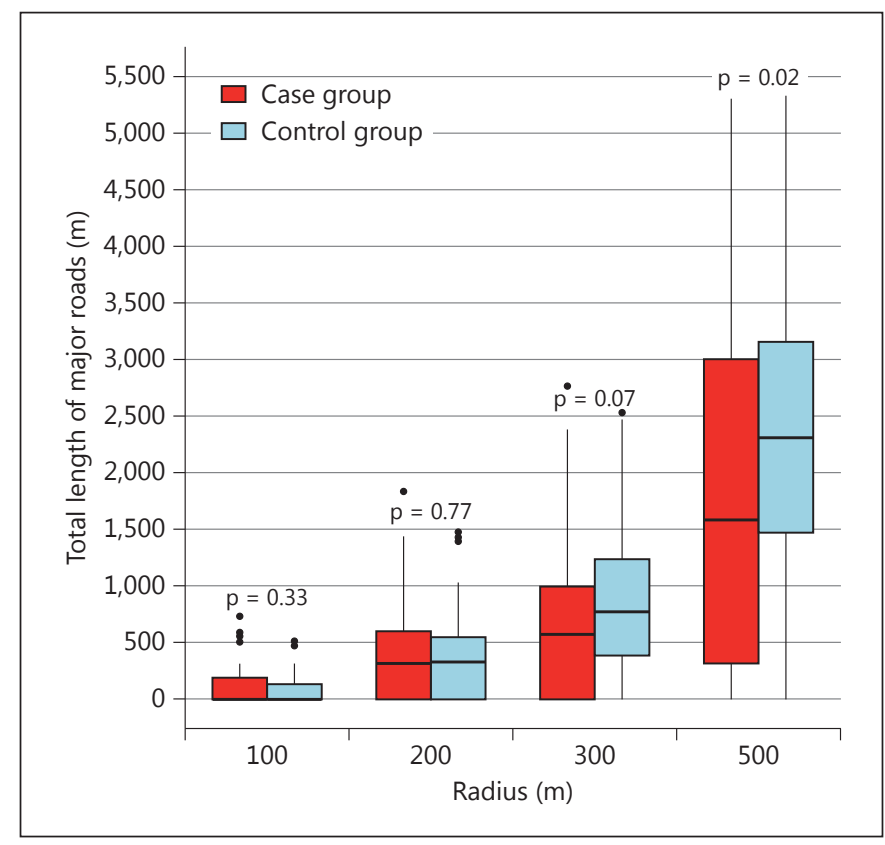

Fig. 1. Total length of major roads around the women's domicile for cases $(n=50)$ and controls $(n=50)$.

\section{Discussion}

There is growing interest in analyzing environmental factors and influences on pregnancy and neonatal outcome [22,31-33]. According to our findings, women who developed late-onset PE were exposed to significantly higher TRAP in general than women who had early-onset PE. Various studies suggest that a late onset of PE impaired trophoblastic invasion of myometrial arteries and is phenotypically balanced unless predisposing factors will set off a cascade of placental and systemic inflammation [12]. In general, it is thought that early-onset PE involves a placental defect, which is not as evident in lateonset PE. It appears that late-onset PE involved a different inflammatory component [34]. The impaired trophoblastic invasion of the placental bed and the following cascade in the early onset of PE might already determine the severity of the disease, and external factors like TRAP become less obvious. Local air pollution may be an important risk factor for the development of late-onset PE. Epidemiological studies highlighted an association between a steeper increase in arterial blood pressure in pregnancy, an increased risk for pregnancy-induced hypertension, $\mathrm{PE}$ and a higher $\mathrm{PM}_{10}$ exposure [22]. Potential pathways

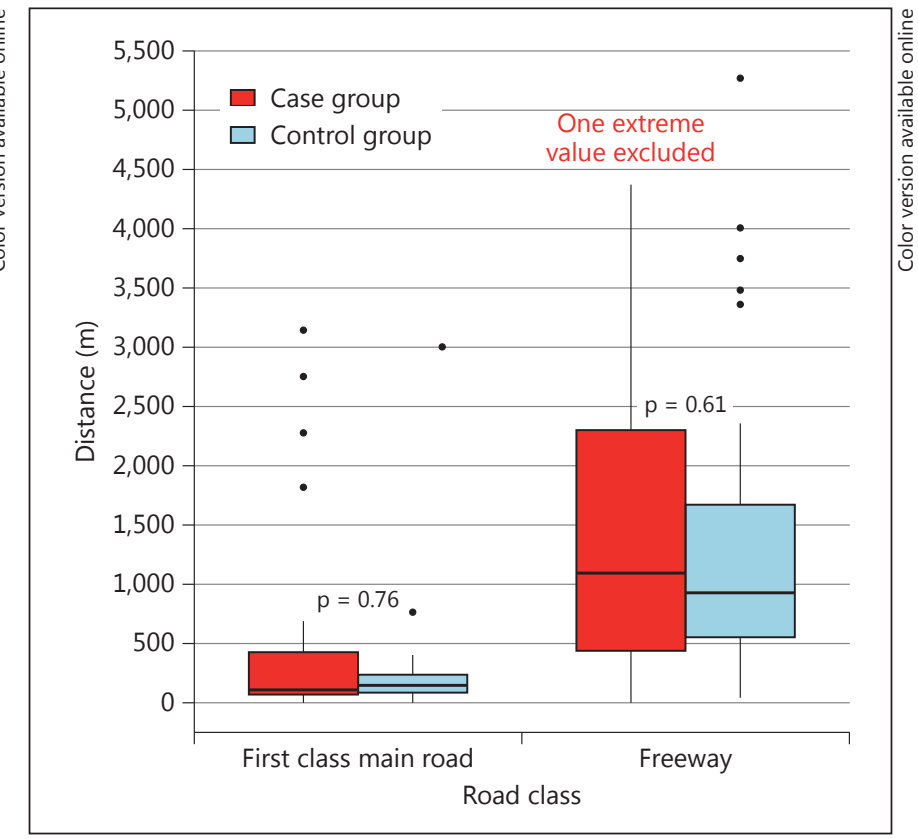

Fig. 2. Distance of the women's domiciles to the nearest freeway and the nearest 'first class' main road for cases $(n=49$; one extreme value was excluded for better presentation of the figure) and controls $(\mathrm{n}=50)$.

Table 2. Description of fetal characteristics

\begin{tabular}{lccc}
\hline Fetal characteristics & Case & Control & p value \\
\hline $\begin{array}{l}\text { Number of children, n } \\
\text { Sex }\end{array}$ & 53 & 53 & 1.00 \\
$\quad$ Male & $29(54.7)$ & $25(47.2)$ & \\
$\quad$ Female & $24(45.3)$ & $28(52.8)$ & \\
Gestational age, days & $250.47 \pm 23.13$ & $279.17 \pm 8.64$ & $<0.001$ \\
Delivery & & & $<0.001$ \\
$\quad$ Preterm & $32(60.3)$ & $0(0)$ & \\
$\quad$ Term & $21(39.7)$ & $50(100)$ & \\
Birth modus & & & $<0.001$ \\
$\quad$ Vaginal & $12(22.6)$ & $47(88.7)$ & \\
$\quad$ Cesarean section & $41(77.4)$ & $6(11.3)$ & \\
Birth weight, g & $2,362.9 \pm 820.1$ & $3,335.9 \pm 419.5$ & $<0.001$ \\
Length, cm & $45.4 \pm 3.6$ & $49.7 \pm 2.0$ & $<0.001$ \\
Transfer to neonatal & & & \\
$\quad$ intensive care unit & $26(49)$ & $0(0)$ & \\
\hline
\end{tabular}

Values represent mean $\pm \mathrm{SD}$ or $\mathrm{n}(\%)$.

for a pro-hypertensive effect of air pollution have been suggested to include an increase in sympathetic tone and/ or the modulation of basal systemic vascular tone as a result of increased endothelin-1 concentrations as well as 


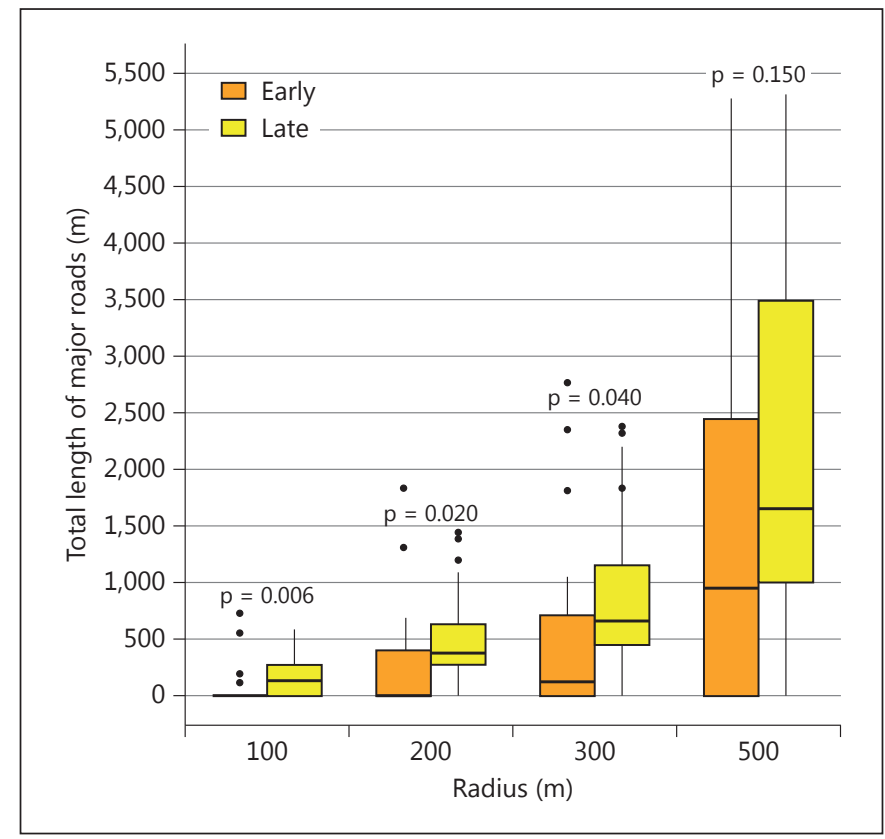

Fig. 3. Total length of major roads around the women's domicile for early- $(n=24)$ and late-onset $(n=26)$ preeclampsia cases.

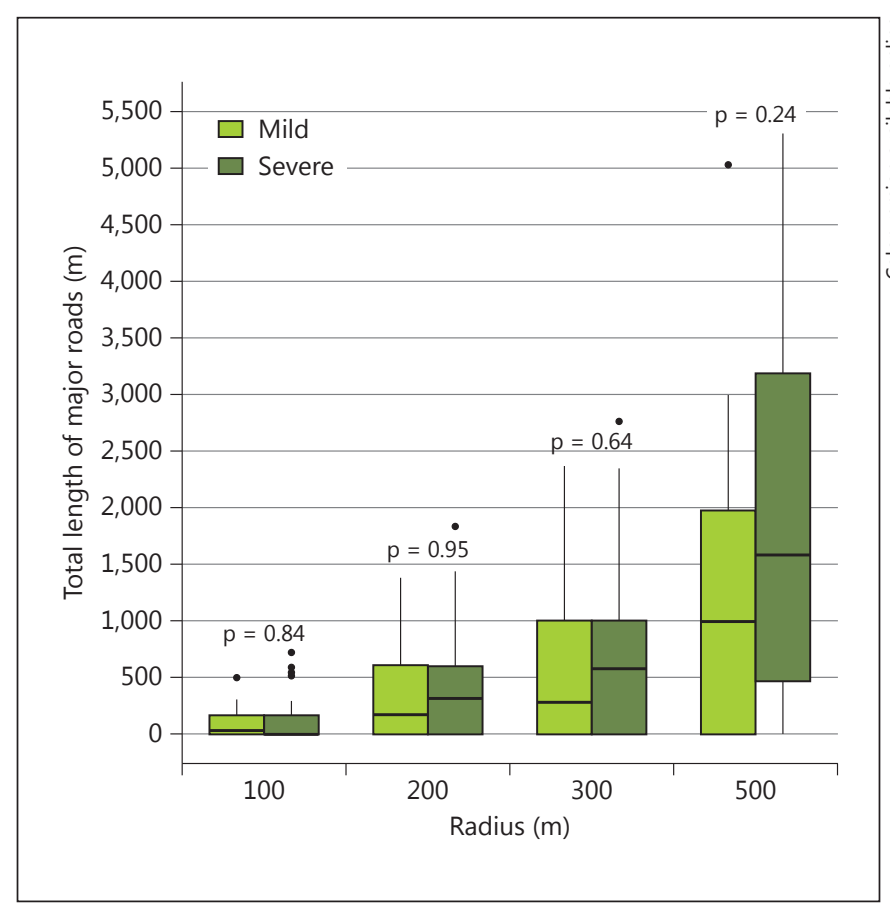

Fig. 5. Total length of major roads around the women's domicile for mild $(n=10)$ and severe $(n=40)$ preeclampsia cases.

Preeclampsia and Air Pollution

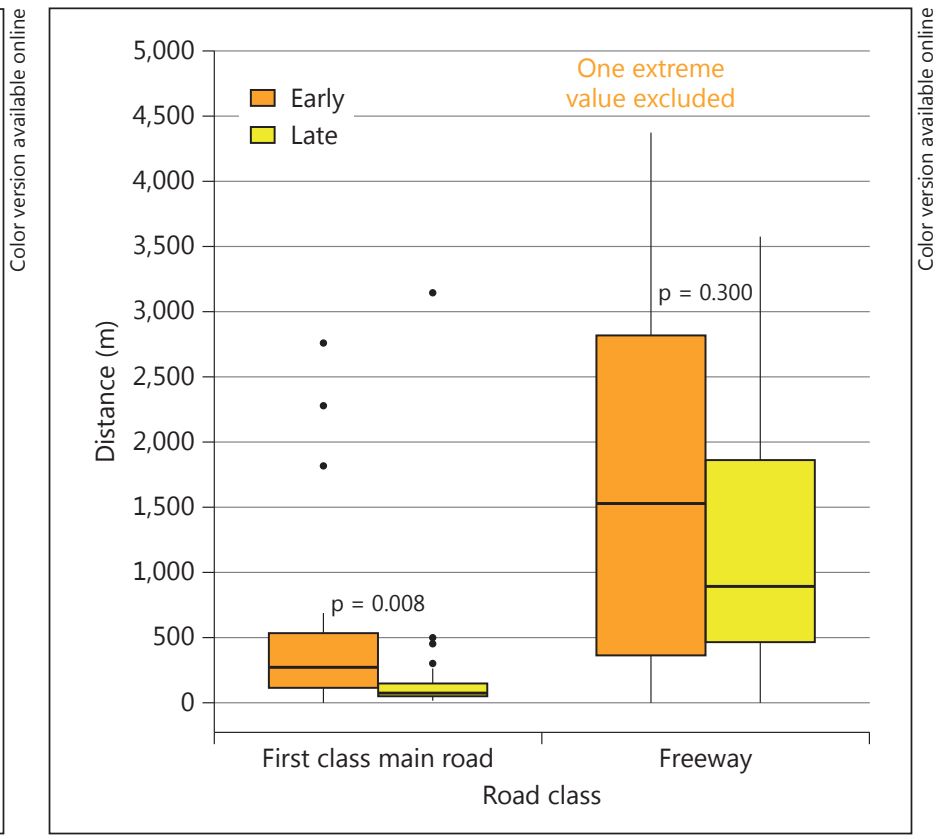

Fig. 4. Distance of the women's domiciles to the nearest freeway and the nearest 'first class' main road for early- $(n=23$, one extreme value was excluded for the better presentation of the figure) and late-onset $(n=26)$ preeclampsia cases.

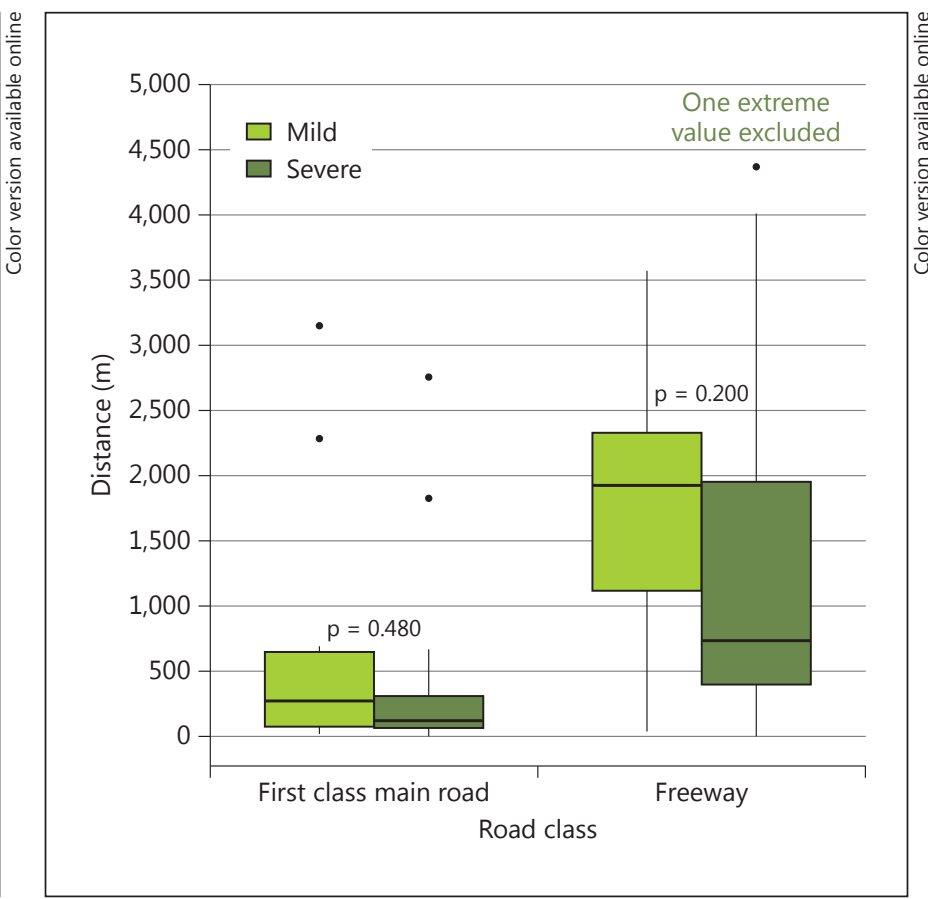

Fig. 6. Distance of the women's domiciles to the nearest freeway and the nearest 'first class' main road for mild $(\mathrm{n}=10)$ and severe ( $n=39$; one extreme value was excluded for better presentation of the figure) preeclampsia cases. 
impairment of nitric oxide-induced vasodilation. Furthermore, exposure to air pollution might result in systemic inflammation, which could predispose to the development of gestational hypertensive disorders [22, 35]. Few studies have investigated PE and gestational hypertension. A California birth cohort study of air pollution investigated $\mathrm{PE}$ based on birth certificates and reported positive associations with higher carbon monoxide (CO) and sulfur dioxide $\left(\mathrm{SO}_{2}\right)$ exposures during pregnancy [27]. Two further studies conducted in the USA reported an increased risk with ambient $\mathrm{CO}, \mathrm{PM}_{2.5}$ or $\mathrm{NO}_{\mathrm{x}}$ exposures [22, 31]. More recently, Lee et al. [7] reported that exposure to particles, mostly $\mathrm{PM}_{2.5}$ and ozone in the first trimester, may increase the risk of developing PE and gestational hypertension. In contrast to these studies, we found no significant association of road density at the women's domicile with an incidence of PE. This may be due to the characteristics of the control group: healthy pregnant women going to the University Hospital have a nearby domicile, i.e. in an urban setting. The larger radiuses (300 and $500 \mathrm{~m}$ ) may reflect an urban versus rural environment rather than a TRAP coming from a closer source (radiuses $100-200 \mathrm{~m}$ ). Nevertheless, considering previous studies $[7,22,27,31]$, data suggest a detrimental effect of near road density on any onset of PE: the study group showed a higher total length of major roads within the shorter radiuses of 100 and $200 \mathrm{~m}$. The lack of statistical significance might be determined by the relatively small number of study participants or the origin of the participants, which belonged mostly to Caucasians. To our knowledge, one research group from Sweden has also investigated possible associations between $\mathrm{PE}$ and air pollution by using road density as a proxy indicator of TRAP [20]. Traffic density within a radius of $200 \mathrm{~m}$ has been observed. According to their results, $\mathrm{PE}$ was associated with high traffic density, but the odds ratio was not significant. Our results were in agreement with the previous research if we only considered radiuses of 100 and $200 \mathrm{~m}$.

No significant evidence was found for an association of local air pollution with the severity of PE in this study. Nevertheless, a potential association between the occurrence of severe PE cases and higher traffic air pollution could be shown.

The current study provides, for the first time, data and references for the local situation in Switzerland. Instead of birth certificates, we used detailed clinical data with accurate gestational age based on a first ultrasound and maternal parameters, which allowed us to classify the 2 subtypes of PE.
To date, there has only been 1 study reporting on the impact of air pollution on early- and late-onset PE separately [36]. They found the strongest associations observed for late-onset $\mathrm{PE}$ in relation to third-trimester exposure to fine particulate pollutants and for early-onset PE.

The present study could replicate a significant difference in exposure to TRAP between early- and late-onset PE. This observation may provide some further indices for the pathogenesis of $\mathrm{PE}$. If the association between air pollution and pregnancy complications represents a causal relation, it would have profound implications for public health, particularly in countries with limited maternal health care.

The retrospective study design bears 2 caveats. First, we did not match for risk factors like hypertension, previous PE or twin pregnancy, which could increase the risk of PE. This could cause bias and has to be considered in the interpretation. Second, since changes of address during pregnancy were not considered in our study, the real duration at the residence of each woman during her pregnancy is actually uncertain. This could be a potential bias for calculating the local air pollution exposure.

The road density is just a proxy for TRAP. However, the roads are the source of TRAP and are the most relevant predictors in the currently most used air pollution models (Land Use Regressions and Dispersion models). The consequence of using a less precise exposure assessment (road density versus $\mathrm{NO}_{2}$ modelling or measuring) could lead to less power and nonsignificant results. We could show that even by using a far more simple approach to estimate 'traffic-related air pollution' exposure, we found evidence of the effect.

\section{Conclusions}

Our study shows that the exposure to TRAP during pregnancy was associated with a significantly increased risk for the development of late-onset PE compared to the early-onset cases. No statistical significance, but a potential association between local air pollution exposure and severity of PE, as well as an association between the occurrence of $\mathrm{PE}$ in general and traffic exposure within radiuses of 100 and $200 \mathrm{~m}$, were observed in this study. More prospective studies with more participants are needed to understand local air pollution as a possible risk factor for late-onset PE and its pathogenesis.

If the association between air pollution and late pregnancy complications represents a causal relation, it would have profound implications for public health, particularly in countries with limited maternal health care [20]. 


\section{Acknowledgements}

We gratefully acknowledge the contribution of the Department of Obstetrics and Fetomaternal Medicine, University Hospital of Basel, for making this study possible. We especially thank Parveen Jenni and Ingrid Wieland for their support and for organizing all the appointments. Thanks to Dr. Stefanie von Felten from the Clinical Trial Unit of the University Hospital of Basel for her nice support in the statistical analysis. Our thanks also go out to Prof. Urs Frey from Basel University Children's Hospital for his dedicated support.

\section{References}

1 Ghulmiyyah L, Sibai B: Maternal mortality from preeclampsia/eclampsia. Semin Perinatol 2012;36:56-59.

2 Staff AC, Benton SJ, von Dadelszen P, et al: Redefining preeclampsia using placenta-derived biomarkers. Hypertension 2013;61: 932-942.

3 Brosens I, Pijnenborg R, Vercruysse L, Romero R: The 'Great Obstetrical Syndromes' are associated with disorders of deep placentation. Am J Obstet Gynecol 2011;204:193-201.

4 Sibai BM: What to expect from expectant management in severe preeclampsia at $<34$ weeks gestation: pregnancy outcomes in developed versus developing countries. Am J Obstet Gynecol 2013;209:400-401.

5 von Dadelszen P, Magee LA, Roberts JM: Subclassification of preeclampsia. Hypertens Pregnancy 2003;22:143-148.

6 Sibai B, Dekker G, Kupferminc M: Preeclampsia. Lancet 2005;365:785-799.

7 Lee PC, Roberts JM, Catov JM, et al: First trimester exposure to ambient air pollution, pregnancy complications and adverse birth outcomes in Allegheny County, PA. Matern Child Health J 2013;17:545-555.

8 Maynard SE, Min JY, Merchan J, et al: Excess placental soluble fms-like tyrosine kinase 1 (sFlt1) may contribute to endothelial dysfunction, hypertension, and proteinuria in preeclampsia. J Clin Invest 2003;111:649658.

9 Roberts JM, Taylor RN, Musci TJ, et al: Preeclampsia: an endothelial cell disorder. Am J Obstet Gynecol 1989;161:1200-1204.

10 Mifsud W, Sebire NJ: Placental pathology in early-onset and late-onset fetal growth restriction. Fetal Diagn Ther 2014;36:117-128.

11 Ornaghi S, Tyurmorezova A, Algeri P, et al Influencing factors for late-onset preeclampsia. J Matern Fetal Neonatal Med 2013;26: 1299-1302.

12 Steegers EA, von Dadelszen P, Duvekot JJ Pijnenborg R: Pre-eclampsia. Lancet 2010; 376:631-644.

13 Huppertz B: Placental origins of preeclampsia: challenging the current hypothesis. Hypertension 2008;51:970-975.
14 Crovetto F, Figueras F, Triunfo S, et al: Added value of angiogenic factors for the prediction of early and late preeclampsia in the first trimester of pregnancy. Fetal Diagn Ther 2014; 35:258-266.

15 Wagner LK: Diagnosis and management of preeclampsia. Am Fam Physician 2004;70: 2317-2324.

16 Lisonkova S, Joseph KS: Incidence of preeclampsia: risk factors and outcomes associated with early- versus late-onset disease. Am J Obstet Gynecol 2013;209:544.e1-544.e12.

17 Jensen S: Mapping human exposure to traffic air pollution using GIS. J Hazard Mater 1998; 61:385-392.

18 Brook RD: Cardiovascular effects of air pollution. Clin Sci (Lond) 2008;115:175-187.

19 Brugge D, Durant JL, Rioux C: Near-highway pollutants in motor vehicle exhaust: a review of epidemiologic evidence of cardiac and pulmonary health risks. Environ Health 2007;6: 23.

20 Malmqvist E, Jakobsson K, Tinnerberg H, et al: Gestational diabetes and preeclampsia in association with air pollution at levels below current air quality guidelines. Environ Health Perspect 2013;121:488-493.

21 Olsson D, Mogren I, Forsberg B: Air pollution exposure in early pregnancy and adverse pregnancy outcomes: a register-based cohort study. BMJ Open 2013;3.

$22 \mathrm{Wu}$ J, Ren C, Delfino RJ, et al: Association between local traffic-generated air pollution and preeclampsia and preterm delivery in the south coast air basin of California. Environ Health Perspect 2009;117:1773-1779.

23 Pedersen M, Stayner L, Slama R, et al: Ambient air pollution and pregnancy-induced hypertensive disorders: a systematic review and meta-analysis. Hypertension 2014;64:494500.

24 Baumwell S, Karumanchi SA: Pre-eclampsia: clinical manifestations and molecular mechanisms. Nephron Clin Pract 2007;106:c72-c81.

25 Kannan S, Misra D, Dvonch J, Krishnakumar A: Exposures to airborne particulate matter and adverse perinatal outcomes: a biologically plausible mechanistic framework for exploring potential effect modification by nutrition. Environ Health Perspect 2006;114: 1636-1642.
26 Pereira G, Haggar F, Shand AW, et al: Association between pre-eclampsia and locally derived traffic-related air pollution: a retrospective cohort study. J Epidemiol Community Health 2013;67:147-152.

27 Woodruff T, Morello-Frosch R, Jesdale B: Air pollution and preeclampsia among pregnant women in California, 1996-2004. Epidemiology 2008; $19:$ :S10.

28 Swisstopo, VECTOR25: Das digitale Landschaftsmodell der Schweiz. Produkteinformation. Swiss Federal Office of Topography, 2007, pp 8-10.

29 Swisstopo: Zeichenerklärungen und weitere Informationen $\mathrm{zu}$ den Landeskarten. Grenzen Bahnen Gelände. Swiss Federal Office of Topography, 2011, p 1.

30 Bundesamt für Landestopografie, swisstopo: Karten. http://www.swisstopo.admin.ch/internet/swisstopo/de/home/products/maps. html.

31 Rudra CB, Williams MA, Sheppard L, et al: Ambient carbon monoxide and fine particulate matter in relation to preeclampsia and preterm delivery in western Washington State. Environ Health Perspect 2011;119:886992.

32 Sapkota A, Chelikowsky A, Nachman K, et al: Exposure to particulate matter and adverse birth outcomes: a comprehensive review and meta-analysis. Air Qual Atmos Health 2010; 23:369-381.

33 Shah PS, Balkhair T: Air pollution and birth outcomes: a systematic review. Environ Int 2011;37:498-516.

34 van der Merwe JL, Hall DR, Wright C, et al: Are early and late preeclampsia distinct subclasses of the disease - what does the placenta reveal? Hypertens Pregnancy 2010;29:457467.

35 van den Hooven EH, de Kluizenaar Y, Pierik $\mathrm{FH}$, et al: Air pollution, blood pressure, and the risk of hypertensive complications during pregnancy: the generation R study. Hypertension 2011;57:406-412.

36 Dadvand P, Figueras F, Basagana X, et al: Ambient air pollution and preeclampsia: a spatiotemporal analysis. Environ Health Perspect 2013;121:1365-1371. 